* Doutor em Direito em 1994 pela Pontifícia Universidade Católica de São Paulo (PUC/SP)

Mestre em Direito em 1989 pela Pontifícia Universidade Católica de São Paulo (PUC/SP)

Graduado em Direito em 1982 pela Pontifícia Universidade Católica de São Paulo (PUC/SP)

** Pós-Doutora em Direito em 2016 pela Universidade de São Paulo (USP)

Doutora em Direito em 2008 pela Pontifícia Universidade Católica de São Paulo (PUC/SP)

Mestre em Direito em 2003 pela Pontifícia Universidade Católica de São Paulo (PUC/SP)

Graduada em Direito em 1997 pela Universidade Paulista (UNIP)

\section{Obrigações Ambientais das Empresas de Celulose eM Face do Direito Brasileiro}

\author{
Environmental Obligations of Pulp Companies in \\ LIGHT OF BRAZILIAN LAW
}

\section{Celso Antonio Pacheco Fiorillo* Renata Marques Ferreira*}

Como citar: FIORILLO, Celso Antonio Pacheco; FERREIRA, Renata Marques. Obrigações ambientais das empresas de celulose em face ao direito brasileiro. Scientia Iuris, Londrina, v. 23, n. 1, p. 180-196, mar. 2019. DOI: 10.5433/2178-8189.2019v2 3n1p180. ISSN: 2178-8189.

Resumo: A celulose, ao ter sua natureza jurídica definida em face da tutela jurídica dos recursos ambientais (bens ambientais), vincula seu uso no âmbito das atividades econômicas ao direito ambiental, ou seja, para que as empresas de celulose possam desenvolver licitamente atividade econômica vinculada ao uso do referido recurso ambiental devem obrigatoriamente obedecer à legislação ambiental balizadora do tema. Daí a necessidade de se realizar a presente pesquisa a partir do método hermenêutico, por meio do levantamento dos trabalhos doutrinários elaborados por estudiosos especializados atuantes no âmbito da matéria investigada, com o objetivo de demonstrar que uma vez observados os regramentos específicos do direito ambiental constitucional (particularmente os Arts. 225, 225, § $1^{\mathrm{o}}$, IV e 225, $\S 3^{\circ}$ da CF) bem como os aspectos estruturais da causa geradora das obrigações ambientais (obrigações de fazer ou não fazer subordinadas aos princípios da prevenção e do poluidor pagador) referidas atividades econômicas podem desenvolver licitamente suas atividades em face de nosso ordenamento jurídico em vigor.

Palavras-Chave: Empresas de celulose. Bens ambientais. Obrigações ambientais. Direito Ambiental Constitucional.

Abstract: Pulp, having its legal nature defined in the face of legal protection of environmental resources (environmental goods), links its use in the scope of economic activities to environmental law, that is, so that pulp companies can lawfully develop economic activity linked to the use of said environmental resource must obey 
the environmental legislation that establishes the theme. Hence the need to carry out the present research from the hermeneutical method, by means of the survey of the doctrinal work elaborated by specialized scholars working within the scope of the subject investigated, with the purpose of demonstrating that once the specific rules of constitutional environmental law have been observed ( particularly Articles 225, 225, § 1, IV and 225, § 3 Federal Constitution ), as well as the structural aspects of the cause of environmental obligations (obligations to do or not to make subordinate to the principles of prevention and the polluter pays) economic activities can lawfully develop their activities in light of our current legal system.

Keywords: Pulp companies. Environmental goods. Environmental obligations. Constitutional Environmental Law. 


\section{INTRODUÇÃO}

Em março de 2018 a mídia anunciou que a maior empresa de celulose do mundo seria criada no Brasil fruto de fusão realizada por empresas já existentes no País.

Assim, possuindo a maior produção de celulose de eucalipto do mundo, com uma capacidade de cerca de 7 milhões de toneladas anuais e podendo atingir capacidade de 11 milhões de toneladas em face da fusão de empresas antes referida, o Brasil tem também destaque na exportação de referida matéria prima sendo certo que, em conjunto com a soja em grão ou farelo, a carne de frango e boi, o açúcar e o café, a celulose foi responsável por $26,8 \%$ das exportações brasileiras.

Observe-se ainda que o saldo de exportação da celulose no ano de 2017 foi de US\$ 2,39 bilhões (SANTANDER, 2018), o que representa uma participação de 2,7\% sendo certo que a extração é feita da madeira de árvores como eucalipto e pinho, que são cultivadas em todo o país.

Destarte verifica-se com clareza que a atuação das empresas antes indicadas, ao depender do uso do aludido bem ambiental (a celulose), somente poderá se desenvolver licitamente em face de necessária obediência ao que determina o direito ambiental constitucional submetendo-se, pois às obrigações estabelecidas em referido complexo de normas. Para tanto entendemos oportuno desenvolver no presente trabalho, a partir da analise normativa da natureza jurídica da celulose como bem ambiental, em que medida se aplicam os princípios do direito ambiental constitucional às atividades econômicas destinadas ao desenvolvimento do processo industrial de aludido insumo em face da obrigação imposta por nossa Lei Maior ao Estado e à própria coletividade. Para tanto foi abordada a causa geradora das obrigações ambientais (obrigações de fazer e não fazer) subordinadas aos princípios ambientais constitucionais da prevenção e do poluidor pagador com destaque para instrumento constitucional do Estudo Prévio de Impacto Ambiental.

A metodologia utilizada, desenvolvida a partir de uma descrição minuciosa e rigorosa do enquadramento jurídico constitucional e infraconstitucional da celulose em face de sua natureza jurídica de bem ambiental, se baseia na análise sistemática dos princípios de direito ambiental constitucional vinculado às atividades econômicas destinadas ao desenvolvimento do processo industrial, estruturado através de pesquisa realizada a partir do método hermenêutico, por meio do levantamento dos trabalhos doutrinários elaborados por estudiosos especializados atuantes no âmbito da matéria investigada e de análise jurídica vinculada ao direito ambiental constitucional assim como das normas infraconstitucionais tudo com o objetivo de adequar de forma satisfatória o enquadramento do tema em face de nosso sistema jurídico em vigor.

\section{A CELULOSE, SUA NATUREZA JURÍDICA DE BEM AMBIENTAL CONSTITUCIONAL E SEU ENQUADRAMENTO NORMATIVO NO ÂMBITO INFRACONSTITUCIONAL}

Polímero de carboidrato que forma a maior parte da matéria vegetal, a celulose, como 
ensina Henry Art (1998, p. 87) "é o principal constituinte da maioria das paredes celulares e, portanto, os tecidos lenhosos" sendo "a matéria - prima usada para fazer papel e raiom" (que como sabemos é nome da seda artificial) constituindo pois insumo fundamental para as empresas, que a extraem a partir de diversos vegetais, como árvores de eucalipto, pinheiro, algodão, bambu, entre outras.

Assim, integrando a flora, a celulose tem natureza jurídica constitucional de bem ambiental (Art.225 da CF) sendo definida no plano infraconstitucional como recurso ambiental em face do que estabelece o Art.3º, V da lei 6938/81 e Art.2 ${ }^{\circ}$, IV da Lei 9985/00.

Recebem, pois, preliminarmente, balizamento normativo em face da tutela jurídica da flora conforme fixado por diversas normas jurídicas de tutela de recursos ambientais existentes em nosso País, como por exemplo, além da já citadas anteriormente, o da Lei 12.651/12(Código Florestal),o da Lei n. 11.428/06(que dispõe sobre a utilização e proteção da vegetação nativa do Bioma Mata Atlântica e dá outras providências) e o da Lei n. 11.284/06(que dispõe sobre a gestão de florestas públicas para a produção sustentável) além de ter seu enquadramento criminal submetido à Lei n. 9.605/98(Crimes Ambientais).

Assim a celulose, ao ter desde logo seu regramento normativo definido em face da tutela jurídica dos recursos ambientais (bens ambientais), vincula seu uso em face de qualquer atividade econômica ao direito ambiental, ou seja, para que as empresas de celulose possam desenvolver licitamente atividade econômica vinculada ao uso do referido recurso ambiental devem obrigatoriamente obedecer a legislação ambiental balizadora do tema. Daí a subordinação de referidas empresas aos comandos normativos de índole ambiental reguladores das atividades econômicas fixadas em nossa Carta Magna em harmonia com a defesa do meio ambiente, art.170, VI c/c art.225 da CF (BRASIL, 1988).

Destarte os superiores dispositivos constitucionais que determinam estruturalmente o balizamento normativo destinado a direcionar a atuação das empresas de celulose, bem como aqueles dispositivos infraconstitucionais estabelecidos em harmonia com as regras superiores antes indicadas, recebem por parte de nossa Constituição Federal comando bem definido.

\section{AS EMPRESAS DE CELULOSE COMO ATIVIDADE ECONÔMICA E O USO DO REFERIDO INSUMO EM FACE DO DIREITO AMBIENTAL CONSTITUCIONAL: A APLICAÇÃO DOS PRINCÍPIOS DE DIREITO AMBIENTAL CONSTITUCIONAL Às ATIVIDADES ECONÔMICAS DESTINADAS AO DESENVOLVIMENTO DO PROCESSO INDUSTRIAL}

Como sabemos a celulose sintetizada naturalmente pelos diversos tipos de vegetais, ao passar por uma série de processos para ser utilizada pela indústria (etapas florestal, de preparação da madeira, de obtenção de celulose, de secagem e de acabamento), configura-se em atividade econômica regrada evidentemente em face da legislação em vigor.

Ao assegurar a todos o livre exercício de qualquer atividade econômica, independentemente 
de autorização de órgãos públicos, salvo nos casos previstos em lei, (parágrafo único do art. 170 da $\mathrm{CF}$ ) nossa Constituição Federal destacou de forma importante a necessidade de se interpretar no plano normativo o significado de referido conceito de atividade em face de seus evidentes reflexos em toda a ordem econômica constitucional particularmente em decorrência do direcionamento estabelecido pelos próprios princípios gerais da atividade econômica (BRASIL, 1988).

Não se trata evidentemente de pura e simplesmente compreender a atividade em face tão somente da economia, a saber, dentro do termo economia, lembrando Antonio Dias Leite (2011, p. 17), como o "quadro físico e institucional dentro do qual se realizam as atividades de produção de bens e serviços requeridos pela sociedade, bem como sua evolução no tempo" mas de compreender de que forma "as atividades de produção de bens e serviços requeridos pela sociedade" tem seu balizamento fixado pela Constituição Federal.

Trata-se a rigor, como lembra Nery (apud FIORILLO; FERREIRA, 2018a) de verificar o que significa atividade no contexto econômico normativo constitucional lembrando, de forma evidentemente menos ampla, dentro de análise doutrinária jurídica e em contexto infraconstitucional, ser a atividade

[...] conceito básico de direito comercial, fenômeno essencialmente humano (Bonfante, Lezioni di storia del commercio). E hoje se pode afirmar que é conceito básico de direito empresarial. A empresa se realiza pela atividade, como o sujeito se realiza por seus atos. Tanto o ato quanto a atividade se exteriorizam por meio de negócios jurídicos, de tal sorte que se afirma que o contrato é o núcleo básico da atividade empresarial.

Com efeito.

Entendida, na lição de Houaiss (2009, p.215) como "qualidade; faculdade ou possibilidade de agir, de se mover, de fazer, empreender coisas; exercício dessa faculdade, ação" em face do que se admite ser ativo ("que exerce ação, que age, que tem a faculdade de agir") o termo atividade também pode ser perfeitamente explicado no âmbito da economia (atividade econômica) como a faculdade de empreender coisas o que facilita evidentemente seu entendimento no contexto da ordem econômica constitucional com evidentes reflexos no direito ambiental constitucional, ou seja, a livre iniciativa passa a atuar em absoluta sintonia com os princípios fundamentais do direito ambiental constitucional.

Assim, como já teve oportunidade de estabelecer o Supremo Tribunal Federal, "é certo que a ordem econômica na Constituição de 1988 define opção por um sistema no qual joga um papel primordial a livre iniciativa. Essa circunstância não legitima, no entanto, a assertiva de que o Estado só intervirá na economia em situações excepcionais”’1.

1 “EMENTA: AÇÃO DIRETA DE INCONSTITUCIONALIDADE. LEI N. 7.844/92, DO ESTADO DE SÃO PAULO. MEIA ENTRADA ASSEGURADA AOS ESTUDANTES REGULARMENTE MATRICULADOS EM ESTABELECIMENTOS DE ENSINO. INGRESSO EM CASAS DE DIVERSÃO, ESPORTE, CULTURAE LAZER. COMPETÊNCIA CONCORRENTE ENTRE A UNIÃO, ESTADOS-MEMBROS E O DISTRITO FEDERAL PARA LEGISLAR SOBRE DIREITO ECONÔMICO. CONSTITUCIONALIDADE. LIVRE INICIATIVA E ORDEM ECONÔMICA. MERCADO. INTERVENCÃO DO ESTADO NA ECONOMIA. ARTIGOS $1^{\circ}, 3^{\circ}, 170$, 205, 208, 215 e 217, $\S 3^{\circ}$, DA CONSTITUIÇÃO DO BRASIL. 1. É certo que a ordem econômica na Constituição 
Destarte, no plano superior constitucional em vigor (princípio fundamental), a livre iniciativa (Art. $1^{\circ}$, IV da CF) como "princípio do liberalismo econômico que defende a total liberdade do indivíduo para escolher e orientar sua ação econômica, independentemente da ação de grupos sociais ou do Estado" implicando em "total garantia da propriedade privada, o direito de o empresário investir seu capital no ramo que considerar mais favorável e fabricar e distribuir os bens produzidos em sua empresa da forma que achar mais conveniente à realização dos lucros" conforme explicação de Paulo Sandroni (2005, p.352), deixa de ser observada em face de sua interpretação inicial e passa a ser admitida em contexto de evidente equilíbrio.

Daí a existência de princípios ambientais constitucionais como os observados nos incisos do Art.170 sendo certo que dentre os referidos princípios, está exatamente o da defesa do meio ambiente natural/recursos ambientais, do meio ambiente cultural/cidades, do meio ambiente artificial/cidades e do meio ambiente do trabalho/saúde ambiental (Art.170, VI da $\mathrm{CF}$ ), cujo conteúdo constitucional está descrito no Art.225 da CF, inclusive mediante tratamento diferenciado conforme o impacto ambiental (Art.225, parágrafo $1^{\circ}$, IV) dos produtos e serviços e de seus processos de elaboração e prestação.

Por via de consequência ao assegurar a todos o livre exercício de qualquer atividade econômica, inclusive evidentemente a atividade econômica destinada ao uso da celulose, nossa Constituição Federal condiciona no plano normativo o exercício de referida atividade não só à defesa do meio ambiente natural/recursos ambientais orientada necessariamente pelos princípios do direito ambiental constitucional, (dentre outros, pelos princípios da prevenção, precaução, poluidor-pagador, etc.) na forma de suas respectivas tutelas jurídicas constitucionais como submete as empresas de celulose às obrigações ambientais derivadas de aludidos comandos normativos conforme a objetiva e segura orientação estabelecida pelo Supremo Tribunal Federal na conhecida ADI $3540^{2}$.

de 1.988 define opção por um sistema no qual joga um papel primordial a livre iniciativa. Essa circunstância não legitima, no entanto, a assertiva de que o Estado só intervirá na economia em situações excepcionais. 2. Mais do que simples instrumento de governo, a nossa Constituição enuncia diretrizes, programas e fins a serem realizados pelo Estado e pela sociedade. Postula um plano de ação global normativo para o Estado e para a sociedade, informado pelos preceitos veiculados pelos seus artigos $1^{\circ}, 3^{\circ}$ e 170. 3. A livre iniciativa é expressão de liberdade titulada não apenas pela empresa, mas também pelo trabalho. Por isso a Constituição, ao contemplá-la, cogita também da "iniciativa do Estado"; não a privilegia, portanto, como bem pertinente apenas à empresa. 4. Se de um lado a Constituição assegura a livre iniciativa, de outro determina ao Estado a adoção de todas as providências tendentes a garantir o efetivo exercício do direito à educação, à cultura e ao desporto [artigos 23, inciso V, 205, $208,215 \mathrm{e} 217$ § $3^{\circ}$, da Constituição]. Na composição entre esses princípios e regras há de ser preservado o interesse da coletividade, interesse público primário. 5. O direito ao acesso à cultura, ao esporte e ao lazer, são meios de complementar a formação dos estudantes. 6. Ação direta de inconstitucionalidade julgada improcedente.” ADI 1950 / SP - SÃO PAULO AÇÃO DIRETA DE INCONSTITUCIONALIDADE Relator: Min. EROS GRAU Julgamento: 03/11/2005 Órgão Julgador: Tribunal Pleno Publicação DJ 02-06-2006 PP-00004 EMENT VOL-02235-01 PP-00052 LEXSTF v. 28, n. 331, 2006, p. 56-72 RT v. 95, n. 852, 2006, p. 146-153 (BRASIL, 2006).

2 A ATIVIDADE ECONÔMICA NÃO PODE SER EXERCIDA EM DESARMONIA COM OS PRINCÍPIOS DESTINADOS A TORNAR EFETIVA A PROTEÇÃO AO MEIO AMBIENTE. - A incolumidade do meio ambiente não pode ser comprometida por interesses empresariais nem ficar dependente de motivações de índole meramente econômica, ainda mais se se tiver presente que a atividade econômica, considerada a disciplina constitucional que a rege, está subordinada, dentre outros princípios gerais, àquele que privilegia a "defesa do meio ambiente" (CF, art. 170, VI), que traduz conceito amplo e abrangente das noções de meio ambiente natural, de meio ambiente cultural, de meio ambiente artificial (espaço urbano) e de meio ambiente laboral. Doutrina". ADI 3540 MC / DF DISTRITO FEDERAL MEDIDA CAUTELAR NA AÇÃO DIRETA DE INCONSTITUCIONALIDADE Relator: Min. CELSO DE MELLO Julgamento: 01/09/2005 Órgão Julgador: Tribunal Pleno Publicação DJ 03-02-2006 PP-00014 EMENT VOL-02219-03 PP-00528 (BRASIL, 2005). 


\section{A OBRIGAÇÃO IMPOSTA PELA CONSTITUIÇÃO FEDERAL AO ESTADO E À PRÓPRIA COLETIVIDADE DE PROTEGER OS BENS AMBIENTAIS EM PROVEITO DO USO COMUM DE BRASILEIROS E ESTRANGEIROS RESIDENTES NO PAÍS: OS DEVERES AMBIENTAIS EM FACE DOS RECURSOS AMBIENTAIS}

Conforme interpretado pelo Supremo Tribunal Federal (ADI 3540), incumbe, ao Estado e à própria coletividade, a especial obrigação de defender e preservar, em benefício das presentes e futuras gerações, o direito ambiental, a saber, as relações jurídicas vinculadas ao meio ambiente natural, ao meio ambiente cultural, ao meio ambiente artificial (espaço urbano) e ao meio ambiente laboral submetem-se à obrigação constitucional antes referida.

O adimplemento de referido encargo, que é irrenunciável na interpretação estabelecida pelo STF, representa a garantia de que não se instaurarão, no seio da coletividade, os graves conflitos intergeneracionais marcados pelo desrespeito ao dever de solidariedade, que a todos se impõe, na proteção desse bem essencial de uso comum das pessoas em geral (o bem ambiental).

Destarte, o uso dos bens ambientais na ordem econômica balizada em nossa Constituição Federal (uso evidentemente autorizado visando a transformação dos bens ambientais em produto ou mesmo serviço), está condicionado não só, evidentemente, ao que determinam os princípios fundamentais constitucionais (Arts. $1^{\circ}$ a $4^{\circ} \mathrm{da} C F$ ), como particularmente às superiores obrigações fixadas diretamente a partir do que determinam os referidos arts. 225 e 170, VI da Constituição Federal dentro de uma perspectiva mais ampla destinada a fundamentar a gênese da obrigação ambiental no plano da denominada relação jurídica ambiental em face do meio ambiente natural (recursos ambientais como bens ambientais tutelados pelo Art.225 da CF) (BRASIL, 1988).

Resta, portanto bem evidenciado que o uso dos bens ambientais no plano da ordem econômica estabelecida em nossa Constituição Federal está condicionado às obrigações fixadas pela Lei Maior, ou seja, para se estabelecer a exata dimensão das obrigações ambientais necessitamos ter clareza que, no plano constitucional, as obrigações ambientais estão vinculadas não só aos recursos ambientais, mas, como adverte Celso Fiorillo (2019) "igualmente a bens ambientais outros também abarcados pela relação jurídica ambiental".

Passemos, pois a uma breve análise da causa geradora das obrigações ambientais.

\section{CAUSA GERADORA DAS OBRIGAÇÕES AMBIENTAIS E O USO DOS BENS AMBIENTAIS NO PLANO CONSTITUCIONAL: AS OBRIGAÇÕES DE FAZER OU NÃO FAZER SUBORDINADAS AOS PRINCÍPIOS AMBIENTAIS CONSTITUCIONAIS DA PREVENÇÃO E DO POLUIDOR PAGADOR}

Aobrigação,como estabeleciaSantos(1953)emanalise do temanoplanoinfraconstitucional e com amparo na lição de Polacco (Obbligazioni, n.1) "é relação jurídica patrimonial em virtude da qual o devedor é vinculado a uma prestação de índole positiva, ou negativa para com o credor. 
Consiste, por conseguinte, a substancia das obrigações em ser alguém constrangido a dar, fazer ou prestar alguma coisa". Sendo em regra "apreciáveis economicamente" e "redutíveis a uma soma em dinheiro", como advertia Beviláqua (1954), se submetem evidentemente à ordem econômica constitucional em vigor (Art.1 $1^{\circ}$,IV c/c Art.170 e segs da CF).

Ao esclarecer, também em plano infraconstitucional, as causas geradoras das obrigações, já advertia Beviláqua (1954, p.17) que as fontes das obrigações (o contrato, o chamado quase contrato, atos ilícitos e vontade unilateral):

[...] admitiriam ainda uma simplificação, se as reduzíssemos a duas: - o ato humano e a lei, elementos que se não devem dissociar de modo completo, porque $o$ ato humano desprovido de sanção legal é juridicamente improfícuo e, por outro lado, a lei exige a insuflução vital da atividade humana, para descer do mundo abstrato, onde paira e rutila, sem o que não conseguirá realizar o fim a que se destina.

Assim, fundamentada diretamente no texto de nossa Lei Maior (Art.225, parágrafos $1^{\mathrm{o}} \mathrm{a}$ $7^{\mathrm{o}}$ e especificamente Arts. $225, \S 1^{\circ}$, IV e $225, \S 3^{\circ}$ da CF) e em face de balizamento que guarda necessariamente harmonia com os princípios gerais da atividade econômica (Art.170, VI), a causa geradora das obrigações ambientais, como destacam Celso Fiorillo e Renata Ferreira (2019, p.116):

[...] está explicita e diretamente relacionada à tutela jurídica constitucional do meio ambiente em face das quatro noções de meio ambiente indicadas pela interpretação do Supremo Tribunal Federal: as obrigações ambientais vinculadas à tutela jurídica do meio ambiente natural(recursos ambientais como bens ambientais tutelados pelo Art.225 da CF), as obrigações ambientais vinculadas à tutela jurídica do meio ambiente cultural(bens culturais como bens ambientais tutelados pelos arts.215/216 da Constituição Federal), as obrigações ambientais vinculadas à tutela jurídica do meio ambiente artificial(a cidade como bem ambiental tutelada pelos arts. 182 s 183 da CF) e as obrigações ambientais vinculadas à tutela jurídica do meio ambiente do trabalho (a saúde como bem ambiental tutelada pelos arts.196 a 200 da CF).

Podendo ser entendida teoricamente a partir da lição Beviláqua (1954, p.51) como "a relação transitória de direito, que nos constrange a dar, fazer ou não fazer alguma coisa, em regra economicamente apreciável, em proveito de alguém que, por ato nosso ou de alguém conosco juridicamente relacionado, ou em virtude de lei, adquiriu o direito de exigir de nós essa ação ou omissão", a obrigação ambiental, em face de sua gênese constitucional, visa "constranger" o Estado e à própria coletividade, a rigorosamente obedecer as superiores balizas normativas no que se refere ao uso dos bens ambientais (recursos ambientais, bens culturais, cidades e saúde). Tratase, portanto de obrigação constitucional via de regra estabelecida num fazer ou não fazer dentro de princípios constitucionais que subordinam o uso dos bens ambientais assegurados em nossa ordem econômica à defesa do meio ambiente (Art.170, VI da CF).

Daí, e sempre em obediência aos mandamentos constitucionais, a aplicação dos 
denominados princípios da prevenção e do poluidor-pagador no que se refere à interpretação e efetividade das obrigações ambientais e, portanto às obrigações ambientais das empresas de celulose.

\section{OBRIGAÇÕES AMBIENTAIS DAS EMPRESAS DE CELULOSE EM FACE DO PRINCÍPIO DA PREVENÇÃO: AS OBRIGAÇÕES PREVENTIVAS E O ESTUDO PRÉVIO DE IMPACTO AMBIENTAL (EPIA)}

Em face da superior orientação constitucional, num primeiro momento, e como regra, impõe-se ao obrigado o dever de arcar com as despesas de prevenção dos danos ao meio ambiente que a sua atividade possa ocasionar (meio ambiente natural, meio ambiente cultural, meio ambiente artificial e meio ambiente do trabalho).

Daí, inclusive, a incumbência constitucional estabelecida ao Poder Público visando exigir, na forma da lei, para instalação de obra ou atividade potencialmente causadora de significativa degradação do meio ambiente, estudo prévio de impacto ambiental, a que se dará publicidade (EPIA art. art. 225, § $1^{\circ}$, IV).

Notamos, portanto que nossa Constituição Federal, visando dar efetividade ao princípio da prevenção, criou um inédito instrumento destinado a fixar obrigação preventiva àqueles que pretendem instalar obra ou mesmo atividade potencialmente causadora de significativa degradação ao meio ambiente (meio ambiente natural, meio ambiente cultural, meio ambiente artificial e meio ambiente do trabalho).

A referida obrigação, por força constitucional, será via de regra sempre exigível daqueles que atuando na ordem econômica capitalista, e evidentemente das empresas de celulose, necessitem usar bens ambientais visando a elaboração de produtos ou mesmo a realização de serviços.

\subsection{As empresas de celulose em face das atividades potencialmente causadoras de significativa degradação do meio ambiente e o estudo prévio de impacto ambiental (Art.225, parágrafo 1, IV)}

Instrumento normativo originário do ordenamento jurídico americano, tomado de empréstimo por outros países, como a Alemanha, a França e, por evidência, o Brasil ,"de gênese e natureza jurídica constitucional e visando assegurar efetividade na tutela jurídica constitucional dos bens ambientais", como destacam Fiorillo, Fereira e Morita (2019), o Estudo Prévio de Impacto Ambiental, como instrumento preventivo estrutural, passou a ser exigido pela Lei Maior de 1988 na forma do que determina o Art.225, $\S 1^{\circ}$, IV a saber:

Art. 225. Todos têm direito ao meio ambiente ecologicamente equilibrado, bem de uso comum do povo e essencial à sadia qualidade de vida, impondo-se ao Poder Público e à coletividade o dever de defendê-lo e preservá-lo para as presentes e futuras gerações. 
$\S 1^{\circ}$ Para assegurar a efetividade desse direito, incumbe ao Poder Público:

IV - exigir, na forma da lei, para instalação de obra ou atividade potencialmente causadora de significativa degradação do meio ambiente, estudo prévio de impacto ambiental, a que se dará publicidade (BRASIL, 1988).

Assim, para assegurar a efetividade da tutela jurídica dos bens ambientais em face das várias relações jurídicas ambientais disciplinadas em nossa Carta Magna (Patrimônio Genético, Meio Ambiental Cultural, Meio Ambiente Digital, Meio Ambiente Artificial/Cidades, Saúde Ambiental/Meio Ambiente do Trabalho e Meio Ambiente Natural) entendeu por bem nossa Constituição Federal determinar obrigatória incumbência ao Poder Público no sentido de exigir do mesmo, na forma da lei, para atividade potencialmente causadora de significativa degradação do meio ambiente, o referido estudo de impacto que deve ser sempre e necessariamente prévio e público.

Destarte, em nosso País, as diferentes atividades previstas em nosso ordenamento jurídico que potencialmente, "suscetível de existir ou acontecer" na lição de Houaiss (2009), possam causar significativa degradação do meio ambiente, a saber, atividades que possam causar "alteração adversa das características do meio ambiente" (Art.3º, II da lei 6938/81) necessitam apresentar referido estudo no sentido de obedecer aos princípios e normas constitucionais anteriormente indicadas.

As empresas de celulose, portanto, em princípio, devem observar o referido comando constitucional.

Claro está que a referida alteração adversa, para restar cabalmente caraterizada, dependerá de cada caso concreto, a saber, dependerá da real situação a ser examinada (Patrimônio Genético, Meio Ambiental Cultural, Meio Ambiente Digital, Meio Ambiente Artificial/Cidades, Saúde Ambiental/Meio Ambiente do Trabalho e Meio Ambiente Natural) assim como deverá ser devidamente avaliada em decorrência de conhecimento técnico especializado, verdadeiro trabalho elaborado por perito conforme clássica lição de Chiovenda (apud PIRES, 2005, p. 20), a saber,

[...] pessoas chamadas a expor ao juiz não só as observações de seus sentidos e suas impressões pessoais sobre os fatos observados, senão também as induções que se devam tirar objetivamente dos fatos observados ou que lhes deem por existentes. Isto faz supor que eles são dotados de certos conhecimentos técnicos ou aptidões em domínios especiais, tais que não devam estar ao alcance, ou no mesmo grau, de qualquer pessoa culta.

Assim atividades potencialmente causadoras de significativa degradação do meio ambiente geram a exigência constitucional de estudo prévio de impacto ambiental, a que se dará a necessária publicidade sendo certo que a partir do RE 627.189 o Poder Público, como adverte Celso Fiorillo (2019) em face da incumbência que lhe foi determinada pelo art. 225, § 1o, IV, deverá analisar os riscos, avaliar os custos das medidas de prevenção e, ao final, executar as ações necessárias, as quais serão decorrentes de "decisões universais, não discriminatórias, motivadas, 
coerentes e proporcionais", como procedimento de gestão de riscos obrigatório nas atividades econômicas vinculadas ao meio ambiente natural/recursos naturais.

Trata-se, por via de consequência, de análise qualitativa e quantitativa, que evidentemente não se reveste de caráter absoluto, a ser aplicada sempre que existirem incertezas científicas sobre a possibilidade de um produto, evento ou serviço desequilibrar o meio ambiente ou atingir a saúde dos cidadãos, tudo com a finalidade de balizar as atividades econômicas-incluindo evidentemente as empresas de celulose- exercidas em harmonia com os princípios destinados a tornar efetiva a proteção ao meio ambiente.

\subsection{A obrigação constitucional de reparar danos causados ao meio ambiente: obrigações ambientais em face do princípio do poluidor pagador}

Podemos identificar no princípio do poluidor - pagador duas órbitas de alcance: a) busca evitar a ocorrência de danos ambientais (caráter preventivo); e b) ocorrido o dano, visa à sua reparação (caráter repressivo).

Desse modo e conforme destacam Celso Fiorillo e Renata Ferreira (2018b, p.173)

[...] num primeiro momento, impõe-se ao poluidor, na condição de obrigado, o dever de arcar com as despesas de prevenção dos danos ao meio ambiente que a sua atividade possa ocasionar. Cabe a ele, além da elaboração do necessário EPIA, o ônus de utilizar instrumentos necessários à prevenção dos danos.

Numa segunda órbita de alcance, esclarece este princípio que, ocorrendo danos ao meio ambiente em razão da atividade desenvolvida, o poluidor será responsável pela sua reparação, ou seja, e conforme advertência do Ministro Marco Aurélio na ADI 3378 "o fato verificado, o dano, porque não se pode cogitar de indenização, a priori, sem a verificação de dano". A obrigatoriedade de reparar o dano está, pois em conformidade com o princípio de direito ambiental constitucional do poluidor-pagador.

A definição do princípio foi dada pela Comunidade Econômica Europeia, que preceitua:

[...] as pessoas naturais ou jurídicas, sejam regidas pelo direito público ou pelo direito privado, devem pagar os custos das medidas que sejam necessárias para eliminar a contaminação ou para reduzi-la ao limite fixado pelos padrões ou medidas equivalentes que assegurem a qualidade de vida, inclusive os fixados pelo Poder Público competente [...] (FIORILLO; FERREIRA, 2015).

Na Constituição Federal de 1988, encontramos o princípio previsto no art. 225, § 3o.:

$\S 3^{\mathrm{o}}$ As condutas e atividades consideradas lesivas ao meio ambiente sujeitarão os infratores, pessoas físicas ou jurídicas, a sanções penais e administrativas, independentemente da obrigação de reparar os danos causados (BRASIL, 1988). 
Vale observar que na órbita repressiva do princípio do poluidor-pagador há incidência da denominada "responsabilidade civil" porquanto o próprio pagamento resultante da poluição não possui caráter de pena, nem de sujeição à infração administrativa, o que, por evidente, não exclui a cumulatividade destas, como prevê a Constituição Federal no referido $§ 3^{0}$ do art. 225.

Com isso, é correto afirmar que o princípio do poluidor-pagador determina a incidência e aplicação de alguns aspectos do regime jurídico da impropriamente denominada "responsabilidade civil” em face dos danos ambientais: a) a prioridade da reparação específica do dano ambiental; b) a denominada responsabilidade chamada civil objetiva; e c) solidariedade para suportar os danos causados ao meio ambiente.

\subsubsection{A prioridade da reparação específica do dano ambiental: retorno ao statu quo ante como critério balizador do uso dos bens ambientais}

Dano, na clássica definição estabelecida por Fischer (1938, p.13), é "todo o prejuízo que o sujeito de direitos sofra através da violação dos seus bens jurídicos" advertindo que "na verdade, dentro do direito positivo o dano só interessa enquanto facto que condiciona a aplicação duma pena ou a constituição dum dever de indemnizar como consequências jurídicas".

Com efeito.

O ressarcimento do dano ambiental vinculado ao inadequado uso dos bens ambientais pode ser feito de duas formas. A primeira delas ocorre com o que se denomina reparação natural ou específica, em que há o ressarcimento "in natura". A segunda, como sublinha Fischer (1938) "é a indenização em dinheiro".

Todavia, isso não significa que a reparação pode, indiferentemente, ser feita por um modo ou outro. Pelo contrário, primeiramente, deve-se verificar se é possível o retorno ao statu quo ante por via da especifica reparação, e só depois de infrutífera tal possibilidade é que deve recair a condenação sobre um quantum pecuniário, até mesmo porque, na lembrança de Wambier (1998, p.82) por vezes, "é difícil a determinação do quantum a ser ressarcido pelo causador do ato feito, sendo sempre preferível a reparação natural, pela recomposição efetiva e direta do ambiente prejudicado". De fato, como lembra Fischer (1938, p.139) “o sistema de reparação natural é evidentemente muito mais adequado para atingir o fim ideal de "restaurar", sendo indiferentemente aplicável aos danos patrimoniais e não patrimoniais, que muitas vezes se confundem entre as consequências dum mesmo acto".

Assim o adequado uso dos bens ambientais com vistas à sua utilização racional e disponibilidade permanente em face de superior orientação constitucional (Art.170, VI c/c Art.225 da CF) orienta a prevalência da reparação in natura influenciando necessariamente todas as normas infraconstitucionais ambientais.

Daí, na lição clássica contida na obra de Enneccerus $(1954$, p.) "la compensación de los 
daños puede hacerse restableciendo efetivamente el estado que existiria de no haberse producido el acontecimento causa del daño(reposicion natural § 249 C.c) o, de manera imperfecta, sólo com dinero a tenor del valor(prestación del interés pecuniário)".

\subsubsection{A denominada responsabilidade chamada "civil" objetiva e a obrigação constitucional de reparar danos causados ao meio ambiente}

Como observado anteriormente, nossa Carta Magna (Art.225, $\S 3^{\circ}$ ) em face de condutas e atividades consideradas lesivas ao meio ambiente (meio ambiente natural, meio ambiente cultural, meio ambiente artificial e meio ambiente do trabalho) sujeita os infratores, pessoas físicas ou jurídicas, na clara manifestação de Celso Fiorillo $(2018$, p.114) "a obrigação de reparar danos causados dentro evidentemente das hipóteses, observando-se caso a caso, previstas em nossa Lei Maior conforme temos aduzido em nossas obras".

Destarte o uso de bens ambientais (os recursos ambientais, os bens culturais, as cidades e a saúde), em desacordo com as superiores orientações do direito ambiental constitucional, submetem os obrigados a reparar o dano causado, tendo em vista, na sempre lembrada lição do Ministro Celso de Mello (ADI 3540) "a especial obrigação de defender e preservar, em benefício das presentes e futuras gerações, esse direito de titularidade coletiva e de caráter transindividual".

Trata-se, pois de responsabilidade fixada por nossa Constituição Federal (e não tão somente por regras infraconstitucionais...), em face de ordem econômica capitalista e dos riscos dela derivados (Art. $1^{\circ}$, IV c/c Art.170 e segs), que visa assegurar a reparação do dano entendido, na lição clássica contida na obra de Enneccerus (1954, p.82) como "toda desventaja que experimentamos em nuestros bienes jurídicos (patrimônio, cuerpo, vida, salud, honor, crédito, bienestar, capacidade de adquisición, etc)". Daí, ao estabelecer comando destinado ao dever de reparar danos causados ao meio ambiente, ter nossa Lei Maior cuidado também da "manera imperfecta, sólo com dinero a tenor del valor (prestación del interés pecuniário)".

Aqui, evidentemente, não estabeleceu nossa Constituição Federal uma regra de "reponsabilidade civil" fundamentada em tradicional lição lembrada por Guido Alpa (2010) e estruturada na clássica teoria da responsabilidade contratual sob o fundamento da culpa e seus requisitos essenciais como ensinava Alvino Lima (1998), a saber, uma regra jurídica associada à doutrina que fundamenta historicamente o subsistema normativo civil vinculado à ideologia de um "direito privado" ou mesmo de quaisquer outras regras estabelecidas a partir de interpretação emanada diretamente de leis federais.

$\mathrm{Na}$ verdade cuidou nossa Carta Magna, isto sim, de deixar explicitada de forma clara e inequívoca comando destinado a reparar danos causados em virtude de condutas e atividades consideradas lesivas ao meio ambiente realizada por infratores (pessoas físicas ou jurídicas) dentro de interpretação própria de gênese constitucional ou seja, e lembrando a clássica lição de Alvino Lima (1998, p.32) citando Josserand (1926), “quem guarda os benefícios que o acaso de sua 
atividade lhe proporciona deve, inversamente, suportar os males decorrentes da mesma atividade".

Por via de consequência e visando estabelecer o uso dos bens ambientais em harmonia com a defesa do meio ambiente dentro de hipóteses de responsabilidade em que não importaria, na adequada interpretação de Celso Fiorillo (2019, p.190) "em nenhum julgamento de valor sobre os atos do responsável bastando que o dano se relacione materialmente com estes atos, porque aquele que exerce uma atividade deve assumir os riscos", nossa Constituição Federal está assentada "na equação binária cujos polos são o dano e a autoria do evento danoso."

Assim determina nossa Constituição Federal, diretamente e independentemente de critérios outros fixados em normas infraconstitucionais (Art.225, $\S 3^{\circ}$ ), que as condutas e atividades consideradas lesivas ao meio ambiente sujeitarão os infratores, pessoas físicas ou jurídicas, a obrigação de reparar os danos causados. Trata-se de dever de reparação em que é irrelevante o dolo ou culpa dos infratores (responsabilidade objetiva) exigindo-se, todavia, necessariamente, além da existência do dano a existência do nexo de causalidade entre o fato e o dano, a saber, "sólo se há de indemnizar aquel daño que constituya uma consecuencia del hecho que obliga a la indemnización" na precisa advertência de Enneccerus (1954).

\subsubsection{A denominada conjunção solidária constitucional: a solidariedade para suportar os danos causados ao meio ambiente}

Tendo sua estrutura jurídica fixada diretamente no texto de nossa Carta Magna, conforme amplamente desenvolvido anteriormente, interpretada a partir dos princípios fundamentais constitucionais (Art. $1^{\circ}$ a IV da CF) e estabelecida em face da defesa do meio ambiente como princípio geral da atividade econômica (Art.170 VI), as obrigações ambientais estão constitucionalmente ligadas aos deveres indicados no Art.225 da Constituição Federal impostos ao Poder Público e à coletividade.

Daí, exatamente no sentido de compatibilizar a ordem econômica constitucional (Art.170 e segs da $\mathrm{CF}$ ) com os deveres estabelecidos pela cláusula constitucional proclamadora do direito fundamental ao meio ambiente (Art.225 da CF), interpretado particularmente pelo que estabelece o Art. $3^{\circ}$, I de nossa Lei Maior, a existência, no plano das obrigações ambientais, da denominada solidariedade passiva. Trata-se de analisar a matéria, como ensinava Beviláqua $(1954$, p.72) em face de análise infraconstitucional no âmbito da denominada conjunção solidária, a saber:

[...] o credor poderá pedir o cumprimento da obrigação a qualquer dos condevedores, sem que este possa alegar o benefício da divisão. Se, porem, preferir, tem a faculdade de fazer valer o seu direito a todos simultaneamente, abrangendo-os, sob o mesmo golpe de ação. Permite-se-lhe ainda escolher, apalpar a força de resistência dos devedores, Demandando um que não se mostre em boas condições de satisfaze - lo plenamente, por debilidade patrimonial, the é lícito recuar, voltando-se para outro, a ver se oferece mais solidez. 
A referida solidariedade, estabelecida como dissemos no plano constitucional, visa assegurar o adimplemento da obrigação ambiental por parte de qualquer dos obrigados admitindose, todavia a faculdade de fazer valer a obrigação a todos simultaneamente.

Constatada, pois a denominada conjunção solidária constitucional determinada pelo Art.225 (Poder Público e coletividade) tem o obrigado, depois de haver satisfeito a obrigação ambiental "o direito de exigir, de cada um de seus consócios na dívida, sua parte respectiva, distribuindo-se igualmente, por todos a porção insolúvel, que porventura restar" conforme ensinava Beviláqua (1954).

\section{CONCLUSÃO}

A celulose, ao ter desde logo seu regramento normativo definido em face da tutela jurídica dos recursos ambientais (bens ambientais), vincula seu uso em face de qualquer atividade econômica ao direito ambiental, ou seja, para que as empresas de celulose possam desenvolver licitamente atividade econômica vinculada ao uso do referido recurso ambiental devem obrigatoriamente obedecer a legislação ambiental balizadora do tema. Verifica-se pois a necessária subordinação de referidas empresas aos comandos normativos de índole ambiental reguladores das atividades econômicas fixadas em nossa Carta Magna, a saber, a subordinação das empresas de celulose às obrigações ambientais, em harmonia com a defesa do meio ambiente (Art.170, VI c/c Art.225 da $\mathrm{CF}$ ) observando-se a aplicação dos princípios do direito ambiental constitucional às atividades econômicas destinadas ao desenvolvimento do processo industrial no âmbito de referidas empresas. Daí a obediência de referidas atividades econômicas à obrigação imposta por nossa Carta Magna no sentido de proteger os bens ambientais em face dos deveres e direitos superiormente fixados com particular atenção para a causa geradora das obrigações ambientais (obrigações de fazer e não fazer) vinculada aos princípios ambientais constitucionais da prevenção e do poluidor pagador com destaque para o uso do instrumento constitucional do Estudo Prévio de Impacto Ambiental (EPIA).

\section{REFERÊNCIAS}

ALPA, Guido. La responsabilità civile: parte generale Utet Giuridica. Torino: Utet Giuridica, 2010.

ART, Henry W. Dicionário de ecologia e ciência ambiental. São Paulo: Companhia Melhoramentos, 1998.

BEVILAQUA, Clovis. Direito das obrigações. 8. ed. Rio de Janeiro: Livraria Francisco Alves, 1954.

BRASIL. [Constituição (1988)]. Constituição da República Federativa do Brasil de 1988. Brasília, DF: Presidência da República, [2016]. Disponível em: http://www.planalto.gov.br/ 
ccivil_03/Constituicao/Constituicao.htm. Acesso em: 5 mar. 2019.

BRASIL. Lei no 6.938, de 31 de agosto de 1981. Dispõe sobre a Política Nacional do Meio Ambiente, seus fins e mecanismos de formulação e aplicação, e dá outras providências. Brasília, DF: Presidência da República, 1981. Disponível em: http://www.planalto.gov.br/ccivil_03/leis/ L6938.htm. Acesso em: 5 mar. 2019.

BRASIL. Lei $\mathbf{n}^{\mathbf{0}}$ 9.605, de 12 de fevereiro de 1998. Dispõe sobre as sanções penais e administrativas derivadas de condutas e atividades lesivas ao meio ambiente, e dá outras providências. Brasília, DF: Presidência da República, 1998. Disponível em: http://www.planalto. gov.br/ccivil_03/LEIS/L9605.htm. Acesso em: 5 mar. 2019.

BRASIL. Lei $\mathbf{n}^{\mathbf{0}}$ 9.985, de 18 de julho de 2000. Regulamenta o art. 225, § 1o, incisos I, II, III e VII da Constituição Federal, institui o Sistema Nacional de Unidades de Conservação da Natureza e dá outras providências. Brasília, DF: Presidência da República, 2000. Disponível em: http://www.planalto.gov.br/ccivil_03/LEIS/L9985.htm. Acesso em: 5 mar. 2019.

BRASIL. Lei $\mathbf{n}^{\mathbf{0}}$ 11.428, de 22 de dezembro de 2006. Dispõe sobre a utilização e proteção da vegetação nativa do Bioma Mata Atlântica, e dá outras providências. Disponível em: http:// www2.mma.gov.br/port/conama/legiabre.cfm?codlegi=526. Acesso em: 5 mar. 2019.

BRASIL. Lei $\mathbf{n}^{\mathbf{0}} \mathbf{1 2 . 6 5 1}$, de 25 de maio de 2012. Dispõe sobre a proteção da vegetação nativa; altera as Leis nos 6.938, de 31 de agosto de 1981, 9.393, de 19 de dezembro de 1996, e 11.428, de 22 de dezembro de 2006; revoga as Leis nos 4.771, de 15 de setembro de 1965, e 7.754, de 14 de abril de 1989, e a Medida Provisória no 2.166-67, de 24 de agosto de 2001; e dá outras providências. Disponível em: http://www.planalto.gov.br/ccivil_03/_ato2011-2014/2012/lei/ 112651.htm. Acesso em: 1 mar. 2019.

BRASIL. Supremo Tribunal Federal. Ação direta de inconstitucionalidade ADI 1950 SP. Ação direta de inconstitucionalidade. Lei n. 7.844/92, do Estado de São Paulo. meia Entrada assegurada aos estudantes regularmente matriculados em estabelecimentos de ensino. Ingresso em casas de diversão, esporte, cultura e lazer. competência concorrente entre a união, estadosmembros e o distrito federal para legislar sobre direito econômico. constitucionalidade. livre iniciativa e ordem econômica. mercado. intervenção do estado na economia. Artigos $1^{\circ}, 3^{\circ}$, 170, 205, 208, 215 e 217, $\S 3^{\circ}$, da Constituição do Brasil. Relator: Eros Grau, 3 de novembro de 2005a. Disponível em: https://stf.jusbrasil.com.br/jurisprudencia/762633/acao-direta-deinconstitucionalidade-adi-1950-sp?ref=juris-tabs. Acesso em: 5 mar. 2019.

BRASIL. Supremo Tribunal Federal. Ação direta de inconstitucionalidade ADI 3540 DF. A atividade econômica não pode ser exercida em desarmonia com os princípios destinados a tornar efetiva a proteção ao meio ambiente. Relator: Min. Celso de Mello, 1 setembro de 2005b.

ENNECCERUS, Ludwig. Derecho de obligaciones. Barcelona: Bosch Casa Editorial, 1954.

FIORILLO, Celso Antonio Pacheco. Curso de direito ambiental brasileiro. 19. ed. São Paulo: Saraiva, 2019.

FIORILLO, Celso Antonio Pacheco. Direito processual ambiental brasileiro: a defesa judicial do patrimônio genético, do meio ambiente cultural, do meio ambiente digital, do meio ambiente artificial, do meio ambiente do trabalho e do meio ambiente natural no Brasil. 7. ed. São Paulo: Saraiva, 2018. 
FIORILLO, Celso Antonio Pacheco; FEREIRA, Paulo; MORITA, Dione Mari. Licenciamento ambiental. 3. ed. São Paulo: Saraiva, 2019.

FIORILLO, Celso Antonio Pacheco; FERREIRA, Renata Marques. Direito ambiental tributário. 4. ed. São Paulo: Saraiva, 2018.

FIORILLO, Celso Antonio Pacheco; FERREIRA, Renata Marques. O agronegócio em face do direito ambiental constitucional brasileiro: as empresas rurais sustentáveis. Rio de Janeiro: Lumen Juris, 2018.

FIORILLO, Celso Antonio Pacheco; FERREIRA, Renata Marques. Segurança alimentar e desenvolvimento sustentável: a tutela jurídica da alimentação e das empresas alimentares em face do direito ambiental brasileiro. Rio de Janeiro: Lumen Juris, 2019.

FISCHER, Hans Albrecht A reparação dos danos no direito civil. Coimbra: Armeio Amado Editor, 1938.

HOUAISS, Antonio. Dicionário Houaiss da língua portuguesa. Rio de Janeiro: Objetiva, 2009.

LEITE, Antonio Dias. A economia brasileira: de onde viemos e onde estamos. Rio de Janeiro: Elsevier, 2011.

LIMA, Alvino. Culpa e risco. 2. ed. São Paulo: Editora dos Tribunais, 1998.

SANDRONI, Paulo. Dicionário de economia do século XXI. Rio de Janeiro: Editora Record, 2005.

SANTANDER. Você sabe quais são os produtos mais exportados pelo Brasil? São Paulo, 6 ago. 2018. Disponível em: https://www.santandernegocioseempresas.com.br/detalhe-noticia/ produtos-mais-exportados-pelo-brasil.html\#. Acesso em: 19 jan. 2019.

SANTOS, João Manoel de Carvalho. Código civil brasileiro interpretado: parte geral (arts.863-927). 6. ed. Rio de Janeiro: Livraria Freitas Bastos, 1953. v. 9.

WAMBIER, Luis Rodrigues. Liquidação do dano. São Paulo: Revista dos Tribunais, 1998.

Como citar: FIORILLO, Celso Antonio PAcheco; FERREIRA, Renata Marques. Obrigações Ambientais das Empresas de Celulose em Face ao Direito Brasileiro. Scientia Iuris, Londrina, v. 23, n. 1, p. 180-196, mar. 2019. DOI: 10.5433/2178-8189.2019v23n1p180. ISSN: 2178-8189.

Recebido em: 29/01/2019.

Aprovado em: 06/03/2019. 